\title{
FORMULATION AND EVALUATION OF NOVEL ANTIBACTERIAL AND ANTI-INFLAMMATORY CREAM CONTAINING MUNTINGIA CALABURA LEAVES EXTRACT
}

\author{
MAHENDRAN SEKAR*, NUR SYAHIRA ABDUL JALIL \\ Department of Pharmaceutical Chemistry, Faculty of Pharmacy and Health Sciences, Universiti Kuala Lumpur Royal College of Medicine \\ Perak, Ipoh - 30450, Malaysia. Email: mahendransekar@unikl.edu.my
}

Received: 11 August 2017, Revised and Accepted: 20 September 2017

\section{ABSTRACT}

Objective: The main objective of the present study was to formulate antibacterial and anti-inflammatory cream using Muntingia calabura leaves extract.

Methods: 500 g of matured leaves of $M$. calabura were extracted with $70 \%$ methanol using maceration method for a week. The antibacterial activity of the extract and formulated cream in different concentration was investigated against two Gram-positive bacteria (Staphylococcus aureus and Bacillus cereus) and two Gram-negative bacteria (Escherichia coli and Pseudomonas aeruginosa) through disc diffusion method. The anti-inflammatory activity of extract and formulated cream was studied using inhibition of albumin denaturation technique.

Results: The antibacterial activity of the methanolic extract was studied in different concentrations (5, 10, and $25 \mathrm{mg} / \mathrm{ml})$ and the formulated cream was studied in the concentration of $(10,25,50$, and $100 \mathrm{mg} / \mathrm{ml})$. The extract showed significant antibacterial activity with all the tested pathogens with a zone of inhibition ranges from $3.33 \pm 0.88-14.60 \pm 0.80 \mathrm{~mm}$. As for the formulated cream, the zone of inhibition for F1 ranged from $0.67 \pm 0.67 \mathrm{~mm}$ to $14.80 \pm 1.17 \mathrm{~mm}$. F2 presented zone of inhibition at $3.40 \pm 1.64 \mathrm{~mm}$ to $15.00 \pm 1.18 \mathrm{~mm}$. The anti-inflammatory activity showed maximum inhibition of $63.93 \pm 5.90,41.83 \pm 5.64$, and $27.20 \pm 2.72$ was observed at $1000 \mu \mathrm{g} / \mathrm{ml}$ for the extract, F2 and F1, respectively. The cream was found to be in stable state after 2 months.

Conclusion: The results showed that the formulated cream can be used for bacterial infections and to reduce inflammation. We recommend this formulation need to be further developed into commercial standards.

Keywords: Muntingia calabura, Kerukup Siam, Disc diffusion method, Albumin denaturation technique, Antibacterial, Anti-inflammatory.

(C) 2017 The Authors. Published by Innovare Academic Sciences Pvt Ltd. This is an open access article under the CC BY license (http://creativecommons. org/licenses/by/4. 0/) DOI: http://dx.doi.org/10.22159/ajpcr.2017.v10i12.21963

\section{INTRODUCTION}

Antibacterial activity refers to substances (medications) that extinguish or slow down the growth of bacteria. A massive number of antibiotics have been revealed to tackle various types of infections. However, microorganisms are continuing to grow resistance to the existing antibiotics. Because of this antibiotic-resistance issue, infectious diseases are still considered as the second leading causes of death globally. In the past few years, antibacterial agents derived from plant metabolites have gradually grown attention. This may due to the emergence of multidrug resistance bacteria and the rise of infectious disease. The alternative way in facing such problem is to use plant secondary metabolite as resistance-modifying agents [1].

Inflammation is a complex biological response of vascular tissues to harmful stimuli. It is also a defensive attempt by the organism to eradicate the injurious stimuli and initiate the healing process. The cells will undergo activation and release inflammatory mediators at the onset of the inflammation [2]. The inflammatory process involves the release of proinflammatory cytokines, prostaglandins, and the formation of reactive oxygen species. However, excessive of these inflammatory mediators lead to maintain inflammation and induce a chronic inflammation. Nonsteroidal anti-inflammatory drugs used as an effort to treat inflammation. Nevertheless, the long-term use of this drug will expose consumer or patient to many side effects including gastrointestinal erosion, peptic ulcers, nephrotoxicity, leukopenia, and allergic manifestations [3].

Muntingia calabura L. or more commonly addressed as "kerukup siam" and "buah ceri kampung" to the Malay. It is native to Central America, western South America, southern Mexico, and the Caribbean but is wildly cultivated in the region of Southeast Asia, including Malaysia [4]. Muntingia as the sole species in the genus Muntingia is a flowering plant native to southern Mexico, the Caribbean, Central America, and western South America south to Peru and Bolivia [5]. The leaves of $M$. calabura are used to treat pain related to a headache, cold, and gastric ulcer or to reduce the prostate gland swelling. Other parts of M. calabura, the roots, and flowers are also claimed to possess medicinal values in Vietnam and Philippines, and used as an emmenagogue, abortifacient, antidyspeptic, antispasmodic, and diaphoretic, and to treat headaches, dyspepsia, and spasms. Countless efforts have been made to scientifically exhibit the medicinal potential of $M$. calabura. The leaves have been scientifically demonstrated to employ various pharmacological activities, namely, antitumor, antinociceptive, anti-inflammatory, antipyretic, antibacterial, antiproliferative, and antioxidant activities. A study suggested the presence of flavonoids in the leaves of the plant is typically implicated in antimicrobial activities. Four types of flavonoids isolated from M. calabura leaf ethyl acetate extracts demonstrated antimicrobial activity against methicillinsensitive $S$. aureus and methicillin-resistant $S$. aureus [1]. It has been proved that other than $M$. calabura retained anti-inflammatory value, it also, as cited from Zakaria et al. [6], plays a role in gastroprotection. The elucidation of the underlying mechanisms of action also places the traditional use of $M$. calabura leaves in gastroprotection on a solid scientific footing. In other study conducted by Zakaria et al., 2014 [7], the plant's leaves appeared to have antinociceptive activity. These activities are attributed to the possible synergistic action of flavonoids, saponins, and tannins present in the extract.

However, there is no formulation has been developed though M. calabura leaves having potential antibacterial and anti-inflammatory 
activities. There are reports stated that the plant extracts used for cosmetic and personal care applications [8]. Hence, the aim of this study is to formulate and evaluate the antimicrobial and anti-inflammatory activity of the cream containing $M$. calabura leaves extract.

\section{METHODS}

Plant collection and authentication

The leaves of M. calabura were collected from Bayan Lepas, Pulau Pinang, Malaysia, and authenticated by botanist.

\section{Preparation of plant extract}

$500 \mathrm{~g}$ of matured leaves that had been air-dried for 1-2 weeks at room temperature $\left(27 \pm 2^{\circ} \mathrm{C}\right)$ were washed and dried. It is then being extracted with $70 \%$ methanol using maceration method for a week with occasional shaking. The extract was further filtered and concentrated using rotary evaporator and stored in a refrigerator at $4^{\circ} \mathrm{C}$ until further use [9]

\section{Formulation of anti-inflammatory cream}

The formulation and composition of the cream were shown in Table 1. The oil phase and water phase were taken in separate beakers and heated up to $70^{\circ} \mathrm{C}$. The oil phase was added in water phase with continuous stirring till oil-in-water is prepared. The cream is formed when the consistency is good and the appearance is opaque. $1 \%$ and $5 \%$ of $M$. calabura leaves extract were mixed with the base along with methylparaben which is a preservative (Table 1 and Fig. 1).

The following parameters were used Evaluation of formulated cream to evaluate the antibacterial and anti-inflammatory cream [10].

\section{Determination of type of emulsion}

The red dye (Ponceau 4R) was mixed with the cream. A drop of the cream was placed on a microscopic slide and examined under a microscope. If the disperse globules appear red the continuous phase colorless, the cream will be oil-in-water $(\mathrm{o} / \mathrm{w})$ type. The reverse condition will be occurring in water-in-oil (w/o) type cream, i.e., the disperse globules appear colorless and the continuous phase red.

\section{pH of the cream}

The $\mathrm{pH}$ meter was calibrated using standard buffer solution. About $0.5 \mathrm{~g}$ of the cream was weighed and dissolved in $50.0 \mathrm{ml}$ of distilled water and its $\mathrm{pH}$ was measured.

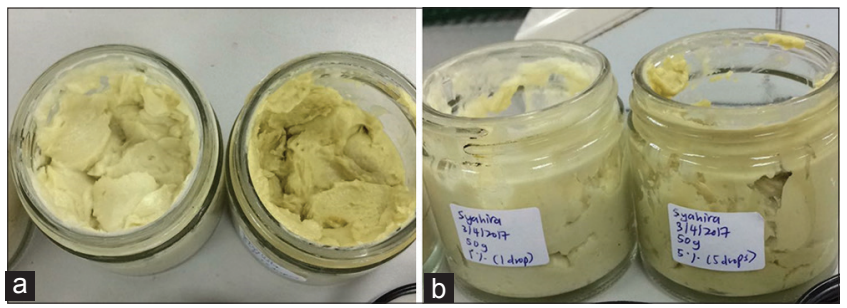

Fig. 1: (a and b) Formulated cream

Table 1: Formulation and composition of antibacterial and anti-inflammatory cream

\begin{tabular}{lll}
\hline Components & Amount (g) & \\
\hline Active ingredient & $1 \%$ cream (20) & $5 \%$ cream (50) \\
$\begin{array}{l}\text { M. calabura leaves extract } \\
\text { Oily phase }\end{array}$ & 1 & 5 \\
Stearic acid & 2.2 & 5.4 \\
Cetyl alcohol & 0.8 & 2.0 \\
Liquid paraffin & 0.8 & 2.0 \\
Aqueous phase & & \\
Water & 14.7 & 36.85 \\
Glycerin & 1.0 & 2.5 \\
Triethanolamine & 0.3 & 0.75 \\
Methylparaben & 0.2 & 0.5 \\
\hline
\end{tabular}

Homogeneity

The formulation was tested for homogeneity by visual appearance and touch.

\section{Appearance}

The appearance of the cream was judged by its color, pearlescence, and roughness and graded.

After feel

Emolliency, slipperiness and the amount of residue left after the application of fixed amount of cream was checked.

\section{Type of smear}

After application of the cream, the type of film or smear formed on the skin was checked.

\section{Removal}

The ease of removal of the cream applied was examined by washing the applied part with tap water

\section{Accelerated stability testing}

Creams were divided into three parts and stability tests performed at $8^{\circ} \mathrm{C} \pm 0.1^{\circ} \mathrm{C}$ in refrigerator and at $25^{\circ} \mathrm{C} \pm 1^{\circ} \mathrm{C}$, and $40^{\circ} \mathrm{C} \pm 1^{\circ} \mathrm{C}$ in incubator with $75 \%$ relative humidity, and the above parameters were observed for 8 weeks at weekly intervals.

\section{Antibacterial activity of extract and formulated cream Test microorganisms}

A panel of four common pathogenic microorganisms was involved in the study, which includes two Gram-positive bacteria (Staphylococcus aureus and Bacillus cereus) and two Gram-negative bacteria (Escherichia coli and Pseudomonas aeruginosa).

\section{Disc diffusion method}

The antibacterial activity of the extract and formulated cream was assessed using disc diffusion method. A suspension of the tested microorganisms was uniformly swabbed on agar plates using sterile cotton swabs. Agar plates were prepared first using agar nutrient medium. It was then poured into a petri dish. Sterile blank discs were individually impregnated to the different concentration of formulated cream $(10,25,50$, and $100 \mathrm{mg} / \mathrm{ml})$ and extract $(5,10$, and $25 \mathrm{mg} / \mathrm{ml})$ and placed onto the inoculated agar plates. The plates were inverted and incubated at $37^{\circ} \mathrm{C}$ for $24 \mathrm{~h}$. The antibacterial activity was evaluated by measuring the diameter of the resulting zone of inhibition against the tested microorganisms in millimeters $[11,12]$.

\section{In vitro anti-inflammatory activity of formulated cream} Inhibition of albumin denaturation

The anti-inflammatory activity of $M$. calabura leaves extract and formulated cream was studied using inhibition of albumin denaturation technique. The reaction mixture was consisting of test extracts and 1\% aqueous solution of bovine albumin fraction, $\mathrm{pH}$ of the reaction mixture was adjusted using a small amount of $1 \mathrm{~N} \mathrm{HCl}$. The sample extracts were incubated at $37^{\circ} \mathrm{C}$ for $20 \mathrm{~min}$ and then heated to $51^{\circ} \mathrm{C}$ for $20 \mathrm{~min}$, after cooling the samples, the turbidity was measured at $660 \mathrm{~nm}$ using an ultraviolet-visible spectrophotometer. The percentage inhibition of protein denaturation was calculated as follows [13].

Percentage inhibition $=($ Abs control - Abs sample $) \times 100) /($ Abs control $)$

\section{RESULTS}

\section{Antibacterial activity}

The methanolic extract of $M$. calabura leaves showed the maximum antibacterial activity against $E$. coli as the zone of inhibition ranges from $9.17 \pm 1.97$ to $14.33 \pm 2.33 \mathrm{~mm}$ (Table 2). Next is B. cereus with zone of inhibition is from $6.03 \pm 1.03$ to $12.50 \pm 1.39 \mathrm{~mm}$, followed by Salmonella enterica $(4.07 \pm 0.64$ to $12.53 \pm 1.57 \mathrm{~mm})$, and $S$. aureus ( $3.33 \pm 0.88$ to $14.60 \pm 0.80 \mathrm{~mm}$ ). The extracts showed a significant 
zone of inhibition when the concentration of the extract was increased (Table 2). Antibacterial activity in formulated cream did show an inhibition. However, the zone of inhibition was not as significant as in the methanolic extract as shown in Table 3. The maximum inhibition is shown in E. coli $(5.33 \pm 1.20,14.80 \pm 1.17 \mathrm{~mm})$, followed by $S$. enterica $(1.00 \pm 0.57,13.90 \pm 0.64 \mathrm{~mm}), B$. cereus $(0.67 \pm 0.67,8.50 \pm 0.76 \mathrm{~mm})$, and $S$. aureus $(0.00,11.00 \pm 1.15 \mathrm{~mm})$. The zone of inhibition did increase with higher concentration. While in Formulation 2, as shown in Table 4, the maximum zone of inhibition can be seen in E. coli $(12.00 \pm 0.58,15.00 \pm 1.18 \mathrm{~mm})$. The second biggest zone of inhibition is against $S$. aureus $(6.17 \pm 0.60,13.40 \pm 0.95 \mathrm{~mm})$, followed by $S$. enterica $(9.13 \pm 0.70,11.40 \pm 1.00 \mathrm{~mm})$, and $B$. cereus $(3.40 \pm 1.64,8.30$ $\pm 0.40 \mathrm{~mm}$ )

\section{In vitro anti-inflammatory activity}

As part of the investigation on the mechanism of the anti-inflammation activity, the ability of the $M$. calabura extract and formulated creams (F1 and F2) to inhibit protein denaturation was studied. It was effective in inhibiting heat-induced albumin denaturation. Maximum inhibition of $63.93 \pm 5.90,41.83 \pm 5.64$, and $27.20 \pm 2.72$ was observed at $1000 \mu \mathrm{g} / \mathrm{ml}$ for the extract, F2, and F1, respectively (Table 5). The lower concentrations do not show significant inhibition. Aspirin, a standard anti-inflammation drug, showed the maximum inhibition $71.20 \pm 4.56$ at the concentration of $100 \mu \mathrm{g} / \mathrm{ml}$ compared with control.

Evaluation of formulated antibacterial and anti-inflammatory cream

The dye test was confirmed that both Formulations 1 and 2 (1\% cream and $5 \%$ cream) were $\mathrm{o} / \mathrm{w}$ type of emulsion cream. The $\mathrm{pH}$ of the formulated cream was found to be in range 4.8-4.9 which is good and recommended $\mathrm{pH}$ for the skin. The formulated antibacterial and antiinflammatory cream were evaluated for several physicochemical tests and the results were shown in Table 6 . All the physicochemical parameters were maintained during the accelerated stability studies at temperatures $8^{\circ} \mathrm{C} \pm 0.1^{\circ} \mathrm{C}$ in the refrigerator and at $25^{\circ} \mathrm{C} \pm 1{ }^{\circ} \mathrm{C}$, $40^{\circ} \mathrm{C} \pm 1^{\circ} \mathrm{C}$ in an incubator for 8 weeks. The results of accelerated stability test showed that there were no any changes in the color of the cream.

Table 2: Antibacterial activity of the methanolic extract of $M$. calabura leaves

\begin{tabular}{|c|c|c|c|c|}
\hline \multirow[t]{3}{*}{ Concentration (mg/ml) } & \multicolumn{4}{|c|}{ Zone of inhibition (mm) } \\
\hline & \multicolumn{2}{|c|}{ Gram-positive } & \multicolumn{2}{|c|}{ Gram-negative } \\
\hline & S. aureus & B. cereus & E. coli & S. enterica \\
\hline 5 & $3.33 \pm 0.88$ & $6.03 \pm 1.03$ & $9.17 \pm 1.97$ & $4.07 \pm 0.64$ \\
\hline 10 & $4.00 \pm 0.58$ & $12.97 \pm 1.29$ & $14.17 \pm 1.48$ & $3.67 \pm 0.88$ \\
\hline 25 & $14.60 \pm 0.80$ & $12.50 \pm 1.39$ & $14.33 \pm 2.33$ & $12.53 \pm 1.57$ \\
\hline Negative control & Nil & $\mathrm{Nil}$ & Nil & Nil \\
\hline \multicolumn{5}{|l|}{ Vancomycin } \\
\hline 10 & Nil & $067 \pm 0.67$ & $5.33 \pm 1.20$ & $1.00 \pm 0.57$ \\
\hline 25 & $6.33 \pm 1.45$ & $5.00 \pm 0.57$ & $8.67 \pm 1.20$ & $0.67 \pm 0.67$ \\
\hline 50 & $8.67 \pm 1.20$ & $5.67 \pm 1.20$ & $11.10 \pm 1.16$ & $5.00 \pm 0.58$ \\
\hline
\end{tabular}

Values are expressed as mean \pm SEM ( $\mathrm{n}=3$ ). $\mathrm{p}<0.05$ between negative control disc and extract treated disc. $\mathrm{p}<0.05$ between negative control disc and standard treated disc, S. aureus: Staphylococcus aureus, B. cereus: Bacillus cereus, E. coli: Escherichia coli, S. enterica: Salmonella enterica, M. calabura: Muntingia calabura S. aureus: Staphylococcus aureus, B. cereus: Bacillus cereus, E. coli: Escherichia coli, S. enterica: Salmonella enterica, M. calabura: Muntingia calabura

Table 3: Antibacterial activity of M. calabura cream, formulation 1 (1\%)

\begin{tabular}{|c|c|c|c|c|}
\hline \multirow[t]{3}{*}{ Concentration $(\mathrm{mg} / \mathrm{ml})$} & \multicolumn{4}{|c|}{ Zone of inhibition (mm) } \\
\hline & \multicolumn{2}{|c|}{ Gram-positive } & \multicolumn{2}{|c|}{ Gram-negative } \\
\hline & S. aureus & B. cereus & E. coli & S. enterica \\
\hline 10 & Nil & $0.67 \pm 0.67$ & $5.33 \pm 1.20$ & $1.00 \pm 0.57$ \\
\hline 25 & $6.33 \pm 1.45$ & $5.00 \pm 0.57$ & $8.67 \pm 1.20$ & $0.67 \pm 0.67$ \\
\hline 50 & $8.67 \pm 1.20$ & $5.67 \pm 1.20$ & $11.10 \pm 1.16$ & $5.00 \pm 0.58$ \\
\hline 100 & $11.00 \pm 1.15$ & $8.50 \pm 0.76$ & $14.80 \pm 1.17$ & $13.90 \pm 0.64$ \\
\hline Negative control & Nil & Nil & Nil & Nil \\
\hline Positive control (vancomycin) & $14.00 \pm 0.69$ & $16.30 \pm 0.68$ & $21.10 \pm 0.60$ & $24.00 \pm 1.45$ \\
\hline
\end{tabular}

Values are expressed as mean \pm SEM $(n=3)$. $p<0.05$ between negative control disc and extract treated disc. $p<0.05$ between negative control disc and standard treated disc

S. aureus: Staphylococcus aureus, B. cereus: Bacillus cereus, E. coli: Escherichia coli, S. enterica: Salmonella enterica, M. calabura: Muntingia calabura

Table 4: Antibacterial activity of M. calabura cream, formulation 2 (5\%)

\begin{tabular}{|c|c|c|c|c|}
\hline \multirow[t]{3}{*}{ Concentration (mg/ml) } & \multicolumn{4}{|c|}{ Zone of inhibition (mm) } \\
\hline & \multicolumn{2}{|c|}{ Gram-positive } & \multicolumn{2}{|c|}{ Gram-negative } \\
\hline & S. aureus & B. cereus & E. coli & S enterica \\
\hline 10 & $6.17 \pm 0.60$ & $4.93 \pm 1.50$ & $12.00 \pm 0.58$ & $11.40 \pm 1.00$ \\
\hline 25 & $9.03 \pm 1.00$ & $3.40 \pm 1.64$ & $13.60 \pm 0.78$ & $10.70 \pm 0.88$ \\
\hline 50 & $10.90 \pm 0.64$ & $6.57 \pm 0.54$ & $15.00 \pm 1.18$ & $11.40 \pm 0.31$ \\
\hline 100 & $13.40 \pm 0.95$ & $8.30 \pm 0.40$ & $13.30 \pm 0.44$ & $9.13 \pm 0.70$ \\
\hline Negative control & Nil & Nil & Nil & Nil \\
\hline Positive control (vancomycin) & $17.20 \pm 0.67$ & $17.40 \pm 0.31$ & $21.40 \pm 0.87$ & $20.50 \pm 1.49$ \\
\hline
\end{tabular}

Values are expressed as mean \pm SEM $(n=3)$. $p<0.05$ between negative control disc and extract treated disc. $p<0.05$ between negative control disc and standard treated disc

S. aureus: Staphylococcus aureus, B. cereus: Bacillus cereus, E. coli: Escherichia coli, S. enterica: Salmonella enterica, M. calabura: Muntingia calabura 
Table 5: Percentage inhibition of $M$. calabura extract and cream on albumin denaturation

\begin{tabular}{llll}
\hline $\begin{array}{l}\text { Concentration } \\
(\boldsymbol{\mu g} / \mathbf{m l})\end{array}$ & \multicolumn{2}{l}{ \% Inhibition } & \\
\cline { 2 - 4 } & Extract & $\mathbf{1 \%}$ cream (F1) & $\mathbf{5 \%}$ cream (F2) \\
\hline 1000 & $63.93 \pm 5.90$ & $27.20 \pm 2.72$ & $41.83 \pm 5.64$ \\
500 & $47.42 \pm 2.07$ & $\mathrm{Nil}$ & $23.88 \pm 4.65$ \\
250 & $27.50 \pm 1.32$ & $\mathrm{Nil}$ & $\mathrm{Nil}$ \\
125 & $11.00 \pm 2.30$ & $\mathrm{Nil}$ & $\mathrm{Nil}$ \\
62.5 & $\mathrm{Nil}$ & $\mathrm{Nil}$ & $\mathrm{Nil}$ \\
31.25 & $\mathrm{Nil}$ & $\mathrm{Nil}$ & $\mathrm{Nil}$ \\
16 & $\mathrm{Nil}$ & $\mathrm{Nil}$ & $\mathrm{Nil}$ \\
8 & $\mathrm{Nil}$ & $\mathrm{Nil}$ & $\mathrm{Nil}$ \\
Negative control & $\mathrm{Nil}$ & $\mathrm{Nil}$ & $\mathrm{Nil}$ \\
Positive control & $71.20 \pm 4.56$ & & \\
(aspirin $100 \mu \mathrm{g} / \mathrm{ml})$ & & & \\
\hline
\end{tabular}

Values are expressed as mean \pm SEM $(n=3)$. $p<0.05$ between negative control disc and extract treated disc. $\mathrm{p}<0.05$ between negative control disc and standard treated disc. M. calabura: Muntingia calabura

Table 6: Physicochemical evaluation of the formulated antibacterial and anti-inflammatory cream

\begin{tabular}{lll}
\hline Parameter & Results & \\
\cline { 2 - 3 } & F1 & F2 \\
\hline Homogeneity & Good & Good \\
Appearance & No change in color & No change in color \\
Odor & Good & Good \\
Spreadability & Good & Moderate \\
After feel & Emollient and & Emollient and slipperiness \\
& slipperiness & \\
Type of smear & Nongreasy & Nongreasy \\
Removal & Easy & Easy \\
Stability & Stable & Stable \\
pH & 4.9 & 4.8 \\
\hline
\end{tabular}

\section{DISCUSSION}

\section{Antibacterial activity}

M. calabura leaves have been scientifically demonstrated to exert various pharmacological activities, namely, antitumor, antinociceptive, anti-inflammatory, antipyretic, antibacterial, antiproliferative, and antioxidant activities [4]. The potential antibacterial activity of the methanolic extract of $M$. calabura leaves together with the formulated cream (F1 and F2) was determined using disc diffusion method against the pathogen of $S$. aureus, B. cereus, E. coli, and P. aeruginosa. From the result, the antibacterial activity of the extract shows a greater zone of inhibition toward Gram-negative bacteria compares to Gram-positive bacteria. Although the most infections did cause by Gram-positive bacteria, such as staphylococci, which according to [12] to be the leading pathogens in clinical practice and a major source of nosocomial infections, food poisoning and wide-range of other disorders. However, new antibiotics are often for Gram-positive bacteria species compared to Gram-negative species because Gram-negative are likely to develop as resistant clones $[14,15]$. The methanolic extract of $M$. calabura leaves showed potent antibacterial activity against the tested microorganisms. This significant result may be due to the presence of active chemical constituents in the plant extract.

\section{Anti-inflammatory activity}

Anti-inflammatory activity of $M$. calabura leaves extract on albumin denaturation method showed a significant activity at the highest concentration. Denaturation of protein is a well-documented cause of inflammation. As part of the anti-inflammatory activity, ability of plant extract (leaves) and formulated cream (F1 and F2) to inhibit protein denaturation signifies apparent potential for anti-inflammatory activity [13]

\section{CONCLUSION}

The antibacterial and anti-inflammatory activity of the methanolic extract of $M$. calabura was evaluated. This activity was preserved when the extract was incorporated into the formulated cream. The cream was intended to be used for the antibacterial and anti-inflammation purpose. However, further studies are warranted to confirm its safety and efficacy.

\section{REFERENCES}

1. Buhian WP, Rubio RO, Valle DL, Martin-Puzon JJ. Bioactive metabolite profiles and antimicrobial activity of ethanolic extracts from Muntingia calabura L. Leaves and stems. Asian Pac J Trop Biomed 2016;6(8):682-5.

2. Ullah HM, Zaman S, Juhara F, Akter L, Mohammed TS, Masum EH, et al. Evaluation of antinociceptive, in-vivo and in-vitro anti-inflammatory activity of ethanolic extract of Curcuma zedoaria rhizome. BMC Complement Altern Med 2014;14:1-12.

3. Ziebrou M, Lompo M, Ouedraogo N, Yaro B, Guissoun I. Antioxidant, analgesic and anti-inflammatory activities of the leafy stems of Waltheria indica L. (Sterculiaceae). J Appl Pharm Sci 2016;6(11):124-9.

4. Yusof MM, Salleh M, Kek TL, Ahmat N, Azmin NN, Zakaria Z. Activity-guided isolation of bioactive constituents with antinociceptive activity from Muntingia calabura L. Leaves using the formalin test. Hindawi Publ Corp 2013;2013:1-9.

5. Vijayanand DS, Thomas AS. Screening of Michelia champacca and Muntingia calabura extracts for potential bioactives. Int J Pharm Sci Res 2016;7(6):266-73.

6. Zakaria ZA, Balan T, Azemi AK, Omar MH, Mohtarrudin N, Ahmad Z, et al. Mechanism(s) of action underlying the gastroprotective effect of ethyl acetate fraction obtained from the crude methanolic leaves extract of Muntingia calabura. BMC Complement Altern Med 2016;16(1):78

7. Zakaria ZA, Sani MH, Cheema MS, Kader AA, Kek TL, Salleh MZ. Antinociceptive activity of methanolic extract of Muntingia calabura leaves: Further elucidation of the possible mechanisms. BMC Complement Altern Med 2014;14:1-12.

8. Purushothaman RS, Guruswamy P, Sabesan G. Synergistic effect of anti-oxidant, anti-tyrosinase and anti-bacterial activities of Tridax procumbens, Lantana camara, Euphorbia hirta and Thevetia peruviana plant extracts for cosmetic and personal care applications. Int J Pharm Pharm Sci 2014;6:91-4.

9. Mahendran S, Ting CP, Syafiq AM, Nalina K. Comparative evaluation of antimicrobial properties of red and white ginger. Asian J Pharm Clin Res 2014;7(1):108-10.

10. Mahendran S, Pavitra S, Afzan M. Formulation and evaluation of novel antiaging cream containing rambutan fruit extract. Int J Pharm Sci Res 2017:8:1000-10

11. Mahendran S, Nurashikin AR. Formulation, evaluation and antibacterial properties of herbal ointment containing methanolic extract of Clinacanthus nutans leaves. Int J Pharm Clin Res 2016;8(8):1170-4.

12. Halima S, Rachida A, Fatima ZE. Antioxidant and antibacterial activities of six Algerian medicinal plants. Int J Pharm Pharm Sci 2016;8(1):364-7

13. Leelaprakash G, Das SM. In-vitro anti-inflammatory activity of methanol extract of Enicostemma axillare. Int J Drug Dev Res 2011;3(3):189-96

14. Kamazeri T, Samah OA, Taher M, Susanti D, Qaralleh H. Antimicrobial activity and essential oils of Curcuma aeruginosa, Curcuma mangga, and Zingiber cassumunar from Malaysia. Asian Pac J Trop Med 2012;5(3):202-9

15. Li XZ, Plesiat $P$, Nikaido $H$. The challenge of efflux-mediated antibiotic resistance in gram-negative bacteria. Clin Microbiol Rev 2015;28(2):337-418. 